\title{
Thermal Distribution System Experiment
}

Richard F. Krajewski

John W. Andrews

George Wei

September 1999

Prepared for:

Building Equipment Division

Office of Building Technologies, State and Community Programs

U.S. Department of Energy

Under Contract No. DE-AC02-98CH10886 


\section{DISCLAIMER}

This report was prepared as an account of work sponsored by an agency of the United States Government. Neither the United States Government nor any agency thereof, nor any of their employees, nor any of their contractors, subcontractors, or their employees makes any warranty, express or implied, or assumes any legal liability or responsibility for the accuracy, completeness, or usefulness of any information, apparatus, product or process disclosed, or represents that its use would not infringe privately owned rights. Reference herein to any specific commercial product, process, or service by trade name, trademark manufacturer, or otherwise, does not necessarily constitute or imply its endorsement, recommendation, or favoring by the United States Government or any agency thereof. The views and opinions of authors expressed herein do not necessarily state or reflect those of the United States Government or any agency, contractor, or subcontractor thereof. 


\section{Abstract}

A laboratory experiment has been conducted which tests for the effects of distribution system purging on system Delivery Effectiveness (DE) as defined in ASHRAE 152P. The experiment is described in its configuration, instrumentation, and data acquisition system. Data gathered in the experiment is given and discussed. The results show that purging of the distribution system alone does not offer any improvement of the system DE. Additional supporting tests were conducted regarding experimental simulations of "buffer" zones and bare pipe and are also discussed 


\section{TABLE OF CONTENTS}

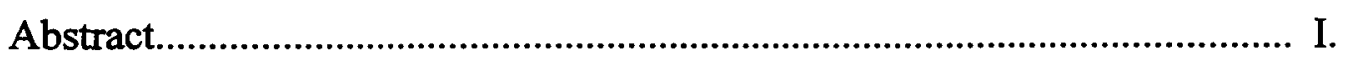

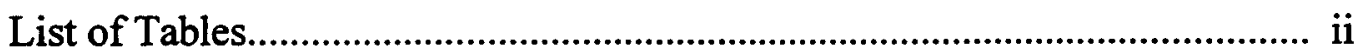

List of Figures............................................................................................. ii

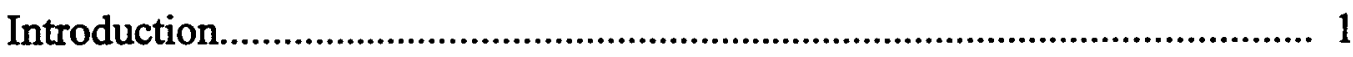

Description of Experimental Setup and Instrumentation.................................... 1

Experimental System Operation................................................................... 3

Physical Geometry of the Experiment.................................................................. 4

Flow Meter Calibration..................................................................................... 5

Individual Tests of a Two-Zone Single Buffer Configuration.............................. 6

Simulation of Buffer Space Piping...................................................................... 9

Tests of the Exaggerated System........................................................................ 13

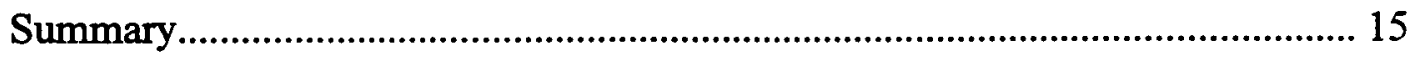

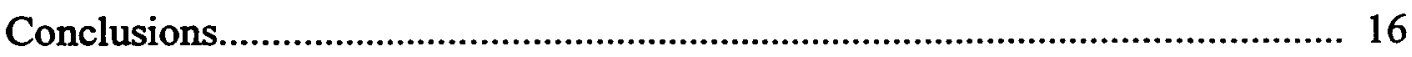

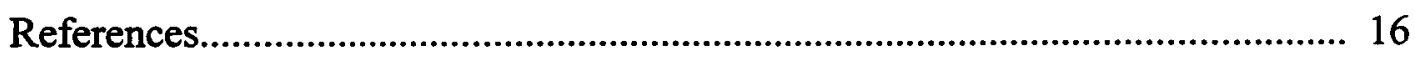

\section{LIST OF TABLES}

1(a) - Test 1 using a lightly insulated coil in a still air gap

(Circulator-15 minutes, boiler in the loop)

1(b) - Test 2 using a lightly insulated coil in a still air gap

(Circulator-20 minutes, bypass valve-5 minutes, boiler out of the loop).

2(a) - Test 1 using a lightly insulated coil in a stirred air gap

(Circulator-10 minutes, boiler in the loop).

2(b) - Test 2 using a lightly insulated coil in a stirred air gap

(Ciculator-20 minutes, bypass valve-10 minutes, boiler out of the loop). 
3(a) - Test 1 using an un-insulated coil in a stirred air gap

(Circulator-10 minutes, boiler in the loop)

3(b) - Test 2 using an un-insulated coil in a stirred air gap

(Circulator-20 minutes, bypass valve-10 minutes, boiler out of the loop)

4(a) - Test 1 using two lightly insulated coils each in a stirred air gap

(Circulator-10 minutes, boiler in the loop).

4(b) - Test 2 using two lightly insulated coils each in a stirred air gap

(Circulator-20 minutes, bypass valve-10 minutes, boiler out of the loop).

5(a) - Base test using two lightly insulated coils each in a stirred air gap

(Circulator-10 minutes, boiler in the loop)

5(b) - Test 2 using two lightly insulated coils each in a stirred air gap (Burner and circulator "on"- 10 minutes, boiler in loop, circulator "off"-5 minute delay, circulator and bypass "on"-10 minutes, boiler out of the loop).

5(c) - Test 2 using two lightly insulated coils each in a stirred air gap (Burner and circulator "on"- 10 minutes, boiler in loop, circulator "off"10 minute delay, circulator and bypass "on"-10 minutes, boiler out of the loop).

\section{LIST OF FIGURES}

1 - Schematic and approximate arrangement of the Thermal Distribution

experiment.........................................................................................................

2 - Plot of the buffer coil water temperature in a lightly insulated pipe coil immersed in cube ice.

3 - Plot of the buffer coil water temperature with a lightly insulated coil suspended in a still air gap.

4 - Plot of the buffer coil water temperature with a lightly insulated coil suspended in a stirred air gap.

5 - Plot of the buffer coil water temperature with an un-insulated coil suspended in a stirred air gap.

6 - Plot of the Zone 1 bare pipe water temperature in still air. 



\section{Introduction}

The purpose of this experiment is to model a hydronic distribution (HD) system and evaluate the effects of water flow duration, geometry, and direction in the $\mathrm{HD}$ system during heating and non-heating periods.

In many conventional HD systems responding to the heating load imposed by the building, heat is liberated through convectors located in the heated space. Heat transfer to the room occurs during the time the circulator pump is operating and also after circulator shutdown, because of the heat stored in the thermal mass of the water in the system. At the same time, during and after circulation, heat is removed from the HD system by heat flow from piping located in areas that may or may not be of benefit the space-heating load. A simple measure of the efficiency of the $\mathrm{HD}$ is the amount of heat delivered to the heated space divided by the heat delivered to the system by the boiler, where both quantities are measured over an integral number of cycles. The system loss is the heat not recovered to meet the heating load.

In ASHRAE Standard 152P [1] this ratio is called delivery effectiveness (DE). The DE ratio does not account for interactions between the distribution system and the rest of the building. In forced air systems these interactions can be both important and complex. In hydronic systems the only interaction that is usually of any significance is thermal regain. This report concentrates on DE and does not concern itself with regain, the amount of which depends on the type of space in which the pipe runs are located.

In general, hydronic systems are expected to have relatively high $\mathrm{DE}$ values, generally exceeding $90 \%$, compared to forced air systems which, as built in most U.S. homes today, tend to have $\mathrm{DE}$ values in the $60 \%-80 \%$ range. The difference lies in the fact that hydronic systems do not leak water whereas air leakage from ducts is a major problem. Pipes are also easer to insulate then ducts because of their smaller perimeter. Nevertheless, some hydronic systems may have only mediocre $\mathrm{DE}$ values if poorly designed with excessive lengths of piping in unconditioned spaces.

This experiment was motivated by preliminary calculations that suggested in such cases, it might be possible to improve $\mathrm{DE}$ by continuing to operate the circulator pump after the call for heat has ended, with provision for bypassing the boiler during this "purge" period. The idea was that hot water in pipes located outside the conditioned space would be moved through the finned-tube baseboard heat-exchange units, and thereby be enabled to give up its heat usefully to the load.

\section{Description of Experimental Setup and Instrumentation}

This experiment used a hydronic system in a two-zone laboratory setting. The system was sized at about half the heat-transfer capacity of a typical residential boiler. The following 
is a brief description that will refer to Figure 1 below. The illustration shows the system as a schematic and an approximate arrangement of the components.

As a heat source the experiment uses an oil-fired prototype 2 section cast-iron boiler manufactured by H.B. Smith under the name of Mestek. This boiler has, according to the manufacturer, an internal volume of $8.3 \mathrm{gal}$. An Ista Model WMZ 2/50-I Btu meter is located around the boiler discharge and return. This was used as a rough check of the boiler output to the system, as calculated using the system flow rate and thermocouples to provide data for a calculational evaluation of the HD system performance. The burner used with this boiler is a Carlin Elite Model EZ-1 using a 0.65 gph nozzle.

The circulator is a Taco Model 007-4 with its "on" and "off" timing under the control of a BNL-built timer. The timer is capable of a wide range of "on" and "off" periods in minutes with control down to 0.1 minutes. The timer is also arranged to provide a lowvoltage signal for event recording of the circulator "on" period and the boiler bypass "on" period during purging of the $\mathrm{HD}$ system. In initial measurements the flow rate in this system was approximately $3.0 \mathrm{gpm}$. This was accurately measured during calibration for the experimental runs.

A Hersey Model R-15 Flow meter and a basic calibration arrangement is located in the system and is able to be isolated from the rest of the system. This calibration used the measurement of a weighed quantity of water to ensure the accuracy of readings from the flow meter.

The baseboard convectors used in this experiment are manufactured by Slant Fin and have a total length of $40 \mathrm{ft}$. equally divided between Zones 1 and 2 . The heat liberation of the baseboard is nominally $500 \mathrm{Btu} / \mathrm{ft}$-hr for the system at $180^{\circ} \mathrm{F}$ average water temperature. Thermocouples are located at the beginning, mid-point, and end of the convector system. Over time the measurement of water temperature and system flow rate were used to calculate the heat liberated to the space from these convectors.

A device to simulate non-recovered heat loss from piping outside the conditioned space is located in the return leg of the system. This so-called "buffer" consisted of a insulated coil of pipe (about $28 \mathrm{ft}$ ) between a perforated inner liner and a larger plastic tank. This annulus was filled with cube ice to chill the air around the coiled pipe. This pipe was lightly insulated with the insulation level adjusted to approximate the heat transfer characteristics of an un-insulated pipe in air. The term "buffer" was used for this setup because the unconditioned space in which portions of a distribution system are located is often referred to as a "buffer" space.

The quantity of ice melt provides a measure of heat loss to the buffer. In addition, an Ista Model WMZ 2/50-I Btu meter around the buffer tank was used to roughly record heat loss to the buffer. In normal mode circulation, water flow from the boiler is directed to the left 
in Figure 1 to the baseboard convector located in Zone 1. The heat loss to the buffer was also measured through integrated measurements of the water temperature in and out of the buffer tank and system flow rate.

The two-way valve and the circulator are each under control of individual BNL built timers as described above. Each of the timers provides relay switched electrical control of the "on" and "off" times to a powered device. The electrical two-way valve, controlled by this timer, is used to divert water flow around the boiler as required.

Direct immersion Type $\mathrm{K}$ thermocouples are located around the experimental system to measure air, water, and buffer space environment temperatures, and their arrangement in relation to system operation is described in the following section. These, together with accurate system flow measurements, provided data for calculating system performance and calibration.

Piping lengths connecting the major components described above have been left short as practical and were left un-insulated. Heat loss from these pipe lengths was assigned to the conditioned space, i.e., considered as useful delivered heat.

Data acquisition was provided through the use of a Molytek Model 2702 32-channel data recorder. Although the recorder has the capability of continuous paper chart recording, it is used in this experiment to send data files to a PC through its ASCII communication port. There are currently 19 Type $\mathrm{K}$ thermocouple channels and two event voltage channels for the circulator and bypass valve. These files were readily imported to a computer spreadsheet for analysis.

\section{Experimental System Operation}

In normal mode under the influence of the circulator the system flow is through the boiler at all times. Referring to Figure 1, the flow exits the boiler and encounters TC1 and the thermistor of the boiler Btu meter. At the two-way valve, port (1) was closed and port (2) was open (un-powered), the flow continues on to Zone 1 and encounters TC15 (bare pipe tests only) at the beginning of a bare pipe run and then TC2 at the beginning of the baseboard convector. The flow goes through $20 \mathrm{ft}$ of convector and encounters TC3 at the midpoint. The flow exits Zone 1 and enters the convector in Zone 2. After flowing through another $20 \mathrm{ft}$ of convector the flow encounters TC4 at the end of the convector. The flow then encounters the thermistor of the buffer Btu meter followed by TC5 and then enters the buffer. The flow gives up heat to the buffer through a coiled pipe suspended in an air gap cooled by cube ice. The midpoint water temperature in the coil is monitored by TC18. The temperature of the buffer environment is measured by TC14. Upon leaving the buffer the flow encounters TC8 and the buffer Btu meter. The flow then encounters the flow meter on its way to the inlet of the circulator. From the discharge of the circulator the flow encounters TC10, the boiler Btu meter, and TC11 at the inlet to the boiler. 


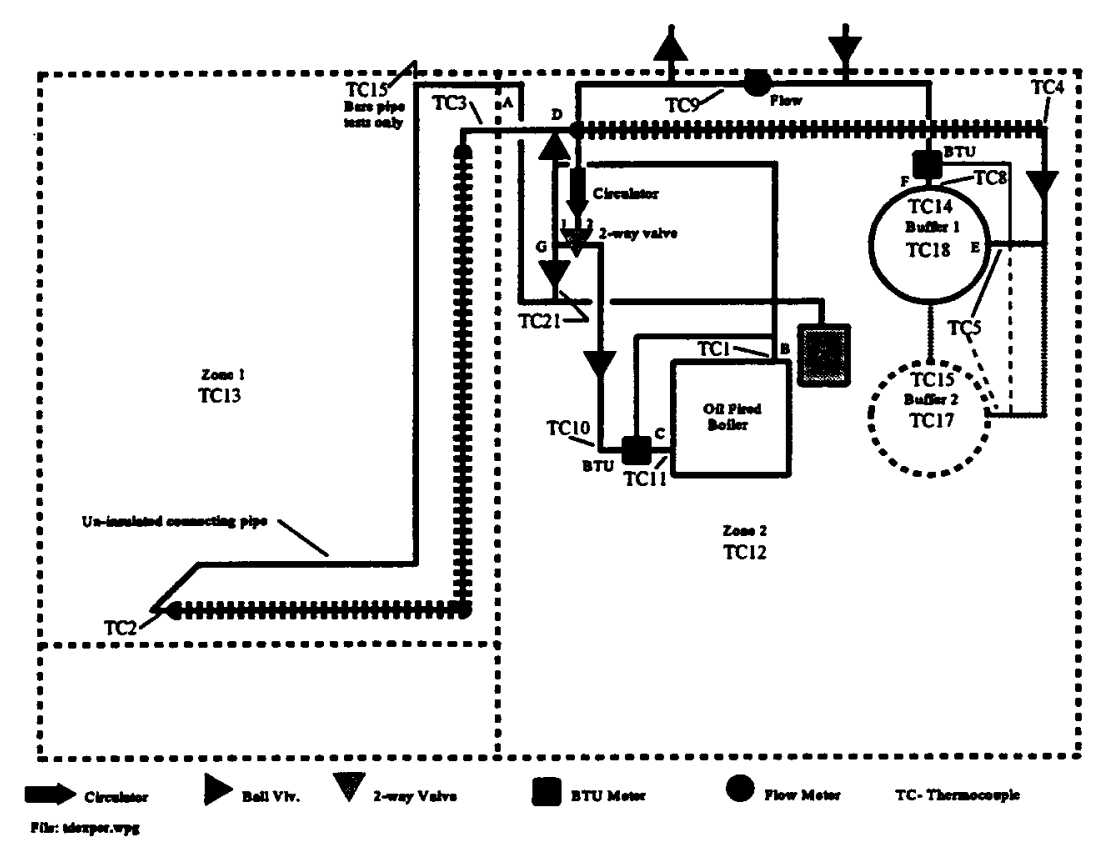

Figure 1 Schematic and approximate arrangement of the Thermal Distribution experiment

In the bypass mode the flow is much the same except with port (1) was open and port (2) was closed at the 2-way valve (powered), the boiler is cut out of the loop. With flow bypassed around the boiler TC1, TC10, and TC11 as well as the boiler Btu meter reading will float.

As can be seen from Figure 1, arrangements were been made for formation of an exaggerated system where the distribution system was forced to bypass Zone 1 completely. In these tests an additional buffer was added to the system. These tests, which will be discussed later, formed a system which halved the distribution size while doubled the size of the buffer zone.

\section{Physical Geometry of the Experiment}

The following is a listing of the pipe segments, location, description, and lengths as measured within the experimental layout:

\begin{tabular}{|c|c|c|c|c|}
\hline Item & Segment & Location & Description & Length $(\mathrm{Ft})$ \\
\hline 1 & $A-I$ & Zone $v$ & Bare & 18.9 \\
\hline 2 & D-I & Dist. Cross to Boiler Out. & Bare pipe in air & 17 \\
\hline 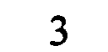 & D-E & Dist. Cross to Buffer 1 & Bare pipe in air & 16.8 (est. 20) \\
\hline
\end{tabular}




$\begin{array}{cclll}4 & \text { D-E } & \text { Dist. Cross to Buffer 1 } & \text { Zone 2 Convector } & 20.9 \\ 5 & \text { D-G } & \text { Circ. Out. to Dist. Cross } & \text { Bare pipe in air } & 13.1 \\ 6 & \text { G-A } & \text { Circ. Out to Zone Wall } & \text { Bare pipe in air } & 10.6 \\ 7 & \text { F-G } & \text { Buffer 1 to Circ. Out } & \text { Bare pipe in air } & 21.3 \\ 8 & \text { F-C } & \text { Buffer 1 to Boiler Inlet } & \text { Bare pipe in air } & 24.9 \\ 9 & \text { E-F } & \text { Coil Length within Buffer } & \text { Bare pipe in air } & 25.5(51) \\ 10 & \text { E-F } & \text { Vertical in Buffer } & \text { Bare pipe in ice } & 3(6) \\ 11 & \text { A-D } & \text { Dist. Cross to Zone Wall } & \text { Zone 1 Convector } & 20.3 \\ 12 & \text { A-D } & \text { Dist. Cross to Zone Wall } & \text { Bare Pipe in Air } & 21.9\end{array}$

The sequential flow through each segment varies depending upon the mode of operation. The numbers shown in parenthesis are lengths for the half distribution/double buffer configuration.

In the normal configuration (boiler in the loop) the flow will utilize items $1,11,12,3,4,9$, 10 , and 8 in that sequence.

In the bypass configuration (boiler out of the loop) the flow will utilize items $1,11,12,3$, $4,9,19,7$, and 6 in that sequence.

With half the distribution, namely Zone 2 in operation, and a double buffer, a different sequence of pipes are used.

In a normal configuration (boiler in the loop) the flow will utilize items $2,3,4,9,10$, and 8 in that sequence. Note that in this case items 9 and 10 are 51 and 6 feet respectively.

In a bypass configuration (boiler out of the loop) the flow will utilize items $2,3,4,9,10,7$, and 6 in that sequence. Note that item 3 is now about 20 feet. The interconnection between the buffers is insulated and is not considered.

\section{Flow Meter Calibration}

The flow meter calibration tests consisted of weigh scale measurements through the meter and a series of timed comparisons of the dial needle display as compared to the accumulated mechanical readout. The weigh scale readings were conducted with supply (cold) water and are compared with the dial display readings as shown in the following Table. The difference is shown as the timed dial reading minus the actual accumulated weight. 


\begin{tabular}{||l|l|l|l|}
\hline $\begin{array}{l}\text { Test } \\
\text { Number }\end{array}$ & $\begin{array}{l}\text { Reading- } \\
\text { gal/min }\end{array}$ & $\begin{array}{l}\text { By Weight- } \\
\text { gal/min }\end{array}$ & Difference \\
\hline 1 & 3.2 & 3.12 & -0.08 \\
\hline 2 & 1.8 & 1.75 & -0.05 \\
\hline 3 & 4.55 & 4.53 & -0.02 \\
\hline 4 & 2.42 & 2.35 & -0.07 \\
\hline 5 & 2.86 & 2.745 & -0.12 \\
\hline 6 & 3.89 & 3.78 & -0.11 \\
\hline
\end{tabular}

Eliminating the highest and lowest reading yields an average of $-0.08 \mathrm{gpm}$ error between actual and readings on the flow meter.

Subsequent timed tests during operation of the system (hot) with the boiler in the loop and bypassed showed a difference in the flow readings. With the boiler in the loop the readings averaged $3.06 \mathrm{gpm}$. With the boiler out of the loop the flow averaged $3.39 \mathrm{gpm}$.

Assuming the $-0.08 \mathrm{gpm}$ error remained constant between cold and hot water flow the average flows used in this analysis are $2.98 \mathrm{gpm}$ and $3.31 \mathrm{gpm}$ respectively.

\section{Individual Tests of a Two-Zone Single Buffer Configuration}

Three pairs of tests were conducted of slightly differing configurations of the Two-Zone Single Buffer system. Tables $1 \mathrm{a}, 1 \mathrm{~b}, 2 \mathrm{a}, 2 \mathrm{~b}$, and $3 \mathrm{a}, 3 \mathrm{~b}$ contain the calculated results of Boiler Heat, Buffer Heat, and Delivery Effectiveness (DE) for five cycles of each test.

Distribution Effectiveness was calculated using a spreadsheet. The equation used was:

$$
\text { Delivery Effectiveness = Boiler Heat }- \text { Buffer Heat }
$$

Boiler Heat

The first pair of tests ${ }^{1}$ used a buffer within which a coil of lightly insulated pipe was suspended in an air gap. This air gap was exposed to, but not filled with, ice. In these two cases the coil was allowed to cool by natural convection. The first of this pair of tests, an un-purged test (boiler in the loop), used a circulator "on" time of 15 minutes and a circulator "off" time of 45 minutes. The second test, a purged test (boiler bypassed and out of the loop), used a circulator "on" time of 20 minutes and an "off" time of 40 minutes. The boiler was bypassed at 15 minutes after the circulator started allowing the distribution system to purge for 5 minutes. The circulator and bypass were shut off together.

1 (Files: td010699.wb2 and td010799.wb2) 
Table 1a --Test 1 using a lightly insulated coil in a still air gap (Circulator - 15 minutes, boiler in the loop)

\begin{tabular}{|c|c|c|c|}
\hline Cycle Num. & $\begin{array}{c}\text { Boiler Heat } \\
\text { (btu) }\end{array}$ & $\begin{array}{c}\text { Buffer Heat } \\
\text { (btu) }\end{array}$ & $\begin{array}{c}\text { Delivery } \\
\text { Effectiveness }\end{array}$ \\
\hline 3 & 9221 & 1206 & 0.86 \\
\hline 4 & 9366 & 1209 & 0.871 \\
\hline 5 & 9631 & 1264 & 0.867 \\
\hline
\end{tabular}

Table $1 \mathrm{~b}$--Test 2 using a lightly insulated coil in a still air gap (Circulator - 20 minutes, bypass valve - 5 minutes, boiler out of the loop)

\begin{tabular}{|c|c|c|c||}
\hline \hline Cycle Num. & $\begin{array}{c}\text { Boiler Heat } \\
\text { (btu) }\end{array}$ & $\begin{array}{c}\text { Buffer Heat } \\
\text { (btu) }\end{array}$ & $\begin{array}{c}\text { Delivery } \\
\text { Effectiveness }\end{array}$ \\
\hline 3 & 9434 & 1270 & 0.865 \\
\hline 4 & 9153 & 1206 & 0.868 \\
\hline 5 & 9197 & 1242 & 0.865 \\
\hline
\end{tabular}

The DE values shown in Table $1 \mathrm{a}$ and $1 \mathrm{~b}$ had averages of 0.869 and 0.866 respectively. The net change from the normal to the distribution system purging operation of this configuration was negligible.

In the second pair of tests ${ }^{2}$ the coil was again lightly insulated but the air gap was stirred using a small air fan. The first of this pair, an un-purged test (boiler in the loop), used a circulator "on" time of 10 minutes and a circulator "off" time of 50 minutes. The second, a purged test (boiler bypassed and out of the loop), used a circulator "on" time of 20 minutes and an "off" time of 40 minutes. The boiler was bypassed at 10 minutes after the circulator started allowing the distribution system to purge for 10 minutes. The circulator and bypass were shut off together.

Table 2a --Test 1 using a lightly insulated coil in a stirred air gap (Circulator - 10 minutes, boiler in the loop)

\begin{tabular}{||c|c|c|c||}
\hline \hline Cycle Num. & $\begin{array}{c}\text { Boiler Heat } \\
\text { (btu) }\end{array}$ & $\begin{array}{c}\text { Buffer Heat } \\
\text { (btu) }\end{array}$ & $\begin{array}{c}\text { Delivery } \\
\text { Effectiveness }\end{array}$ \\
\hline 2 & 7935 & 1383 & 0.826 \\
\hline 3 & 7660 & 1352 & 0.823 \\
\hline 4 & 7385 & 1193 & 0.838 \\
\hline 5 & 7439 & 1203 & 0.838 \\
\hline 6 & 7572 & 1331 & 0.824 \\
\hline
\end{tabular}

2 (Files: td011299.wb2 and td01 1399.wb2) 
Table $2 \mathrm{~b}$--Test 2 using a lightly insulated coil in a stirred air gap

(Circulator - 20 minutes, bypass valve -10 minutes, boiler out of the loop)

\begin{tabular}{||c|c|c|c||}
\hline Cycle Num. & $\begin{array}{c}\text { Boiler Heat } \\
\text { (btu) }\end{array}$ & $\begin{array}{c}\text { Buffer Heat } \\
\text { (btu) }\end{array}$ & $\begin{array}{c}\text { Delivery } \\
\text { Effectiveness }\end{array}$ \\
\hline 2 & 7411 & 1224 & 0.835 \\
\hline 3 & 7373 & 1246 & 0.831 \\
\hline 4 & 7568 & 1294 & 0.829 \\
\hline 5 & 7515 & 1421 & 0.811 \\
\hline 6 & 7583 & 1526 & 0.799 \\
\hline
\end{tabular}

The DE values shown in Table $2 a$ and $2 b$ had averages of 0.830 and 0.821 respectively. This showed slight but statistically insignificant reduction in DE from the normal to the purging operation for configuration.

In the third pair of tests ${ }^{3}$ the pipe coil was un-insulated and the air gap was again stirred using an air fan. The first of this pair, an un-purged tests (boiler in the loop), used a circulator "on" time of 10 minutes and a circulator "off" time of 50 minutes. The second, a purged test (boiler bypassed and out of the loop), used a circulator "on" time of 20 minutes and an "off" time of 40 minutes. The boiler was bypassed at 10 minutes after the circulator started allowing the distribution system to purge for 10 minutes. The circulator and bypass were shut off together.

Table 3a --Test 1 using an un-insulated coil in a stirred air gap (Circulator - 10 minutes, boiler in the loop)

\begin{tabular}{||c|c|c|c||}
\hline Cycle Num. & $\begin{array}{c}\text { Boiler Heat } \\
\text { (btu) }\end{array}$ & $\begin{array}{c}\text { Buffer Heat } \\
\text { (btu) }\end{array}$ & $\begin{array}{c}\text { Delivery } \\
\text { Effectiveness }\end{array}$ \\
\hline 2 & 8203 & 1581 & 0.807 \\
\hline 3 & 8111 & 1614 & 0.801 \\
\hline 4 & 7478 & 1463 & 0.811 \\
\hline 5 & 7761 & 1449 & 0.813 \\
\hline 6 & 7826 & 1465 & 0.813 \\
\hline
\end{tabular}

3 (Files: td012999.wb2 and td020299.wb2) 
Table $3 \mathrm{~b}$-Test 2 using an un-insulated coil in a stirred air gap (Circulator - 20 minutes, bypass valve - 10 minutes, boiler out of the loop)

\begin{tabular}{||c|c|c|c||}
\hline Cycle Num. & $\begin{array}{c}\text { Boiler Heat } \\
\text { (btu) }\end{array}$ & $\begin{array}{c}\text { Buffer Heat } \\
\text { (btu) }\end{array}$ & $\begin{array}{c}\text { Delivery } \\
\text { Effectiveness }\end{array}$ \\
\hline 2 & 8119 & 1618 & 0.801 \\
\hline 3 & 7601 & 1521 & 0.8 \\
\hline 4 & 7742 & 1505 & 0.806 \\
\hline 5 & 7890 & 1597 & 0.798 \\
\hline 6 & 8020 & 1629 & 0.797 \\
\hline
\end{tabular}

The $\mathrm{DE}$ values shown in Table $3 \mathrm{a}$ and $3 \mathrm{~b}$ had averages of 0.809 and 0.800 respectively. This showed slight but again insignificant reduction in $\mathrm{DE}$ from the normal to the purging operation of this configuration.

The above results will be compared later in this report to that of an exaggerated system. This exaggerated system incorporated half of the distribution, namely Zone 2 and a pair of buffers. Using what we learned about the coil conductance, a lightly insulated pipe coil suspended in a stirred air gap was used in each buffer.

\section{Simulation of Buffer Space Piping}

A bare 3/4-inch pipe in still air is expected to have a conductance of $0.4 . \mathrm{Btu} / \mathrm{hr}-\mathrm{F}-\mathrm{ft}$ pipe and a Thermal Capacitance of $0.24 \mathrm{Btu} / \mathrm{F}$-ft pipe. The rationale for these values is given in Section 10.4 of BNL Report 63200 [2]. The time constant can be calculated using the following equation:

$$
\text { Time Constant }(R C) h r=\frac{\text { Thermal Capacitance }(C \text { Btu/F-ft pipe }}{\text { Conductance }(U) \text { Btu/hr-F-ft pipe }}=\frac{C}{U}
$$

Using the values taken from the above report the calculated time constant for a $3 / 4$-inch pipe filled with water in still air is about $0.6 \mathrm{hrs}$. The time constant of this water/pipe combination can be taken as the time required for the temperature of the combination to decay to $37 \%$ of some initial value.

$$
\text { Rearranging terms, } \mathrm{U}=\frac{\mathrm{C}}{\mathrm{RC}}
$$




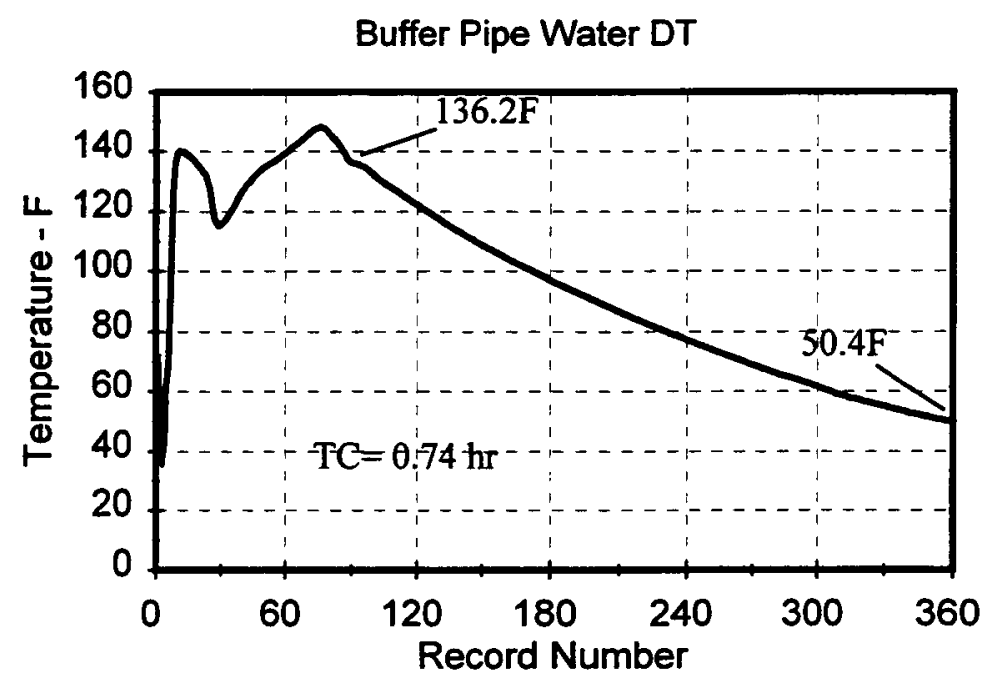

Figure 2.- Plot of the buffer coil water temperature in a lightly insulated pipe coil immersed in cube ice

The original design of the buffer had a lightly insulated pipe coil totally immersed in cube ice. A quick inspection of the data showed a higher than expected heat loss from the coiled pipe. It was assumed that the light insulation was getting wet from the melting ice and therefore a change in the buffer configuration was made to permit the coil to be suspended in air and not in contact with the ice. The buffer coil water temperature decay data gathered during shakedown tests is shown in Figure 2 resulted from later examination.

This detailed examination showed that the original configuration during shakedown actually showed a lower conductance for the pipe coil then that predicted for bare pipe in air. It is possible that the cube ice was acting as additional insulation for pipe coil. The time constant was $0.74 \mathrm{hrs}$. Using the above equation the calculated conductance for the original pipe coil in cube ice was $0.32 \mathrm{Btu} / \mathrm{hr}-\mathrm{F}-\mathrm{ft}$ pipe.

As discussed earlier, based on the erroneous assumption that the buffer was absorbing too much heat, the configuration for the buffer was changed. The new configuration allowed the water coil to be suspended in an air gap. This air gap was cooled by exposure to a central bed of cube ice in the buffer. An analysis of the coil water temperature during the three tests discussed earlier is shown in Figures 3, 4 and 5.

During the first test, the lightly insulated buffer coil was suspended in a still air gap. A single thermocouple, which measured water temperature directly, had been positioned in the center of the coil length. The measured time constant of the water is assumed to be nearly that of the entire water/pipe combination due to the high heat capacity of the water relative to that of the pipe metal. As shown in Figure 3, the measured time constant for the 
pipe coil was about $0.61 \mathrm{hrs}$ and a calculated conductance of $0.39 \mathrm{Btu} / \mathrm{hr}-\mathrm{F}-\mathrm{ft}$ pipe. In hindsight this is in very good agreement with theory.

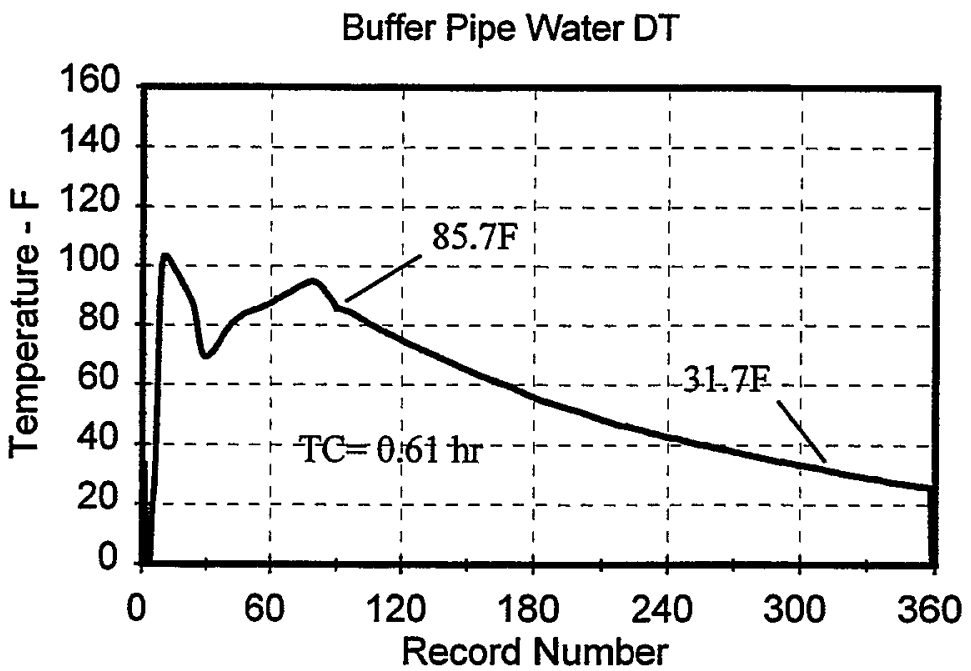

Figure 3 - Plot of buffer coil water temperature with the lightly insulated coil suspended in a still air gap

The next test, using a buffer coil suspended in a stirred air gap, showed similar results. Here the measure time constant, shown in Figure 4, was $0.58 \mathrm{hrs}$ with a calculated conductance of $0.41 \mathrm{Btu} / \mathrm{hr}-\mathrm{F}-\mathrm{ft}$ pipe.

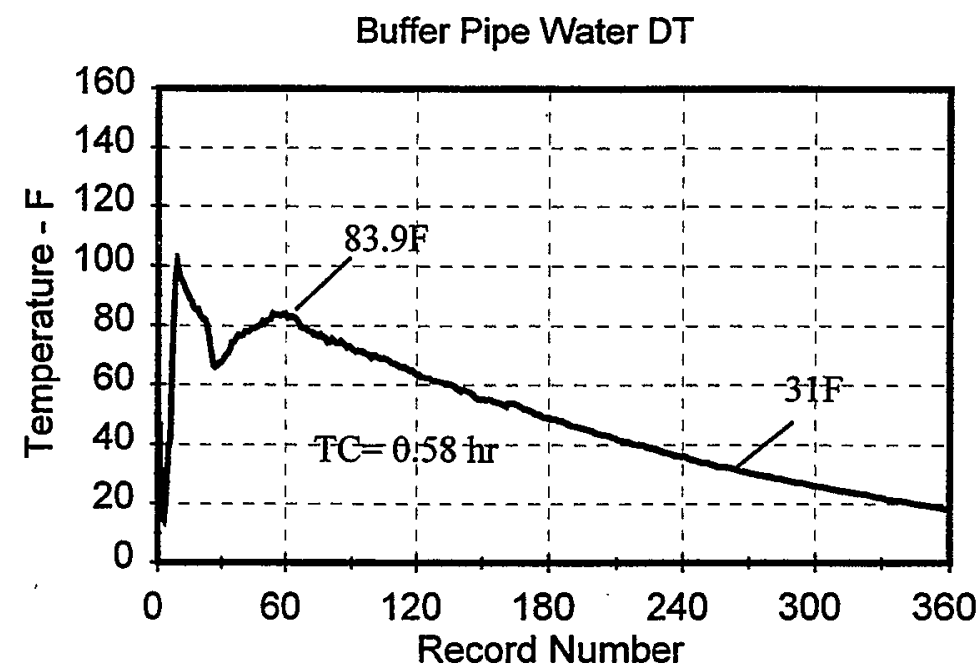

Figure 4 - Plot of buffer coil water temperature with a lightly insulated coil suspended in a stirred air gap 
In the third test, using an un-insulated buffer pipe coil suspended in a stirred air gap, the results showed that the heat loss from the pipe coil was higher than that of the previous two tests. The measured time constant, shown in Figure 5 was $0.41 \mathrm{hrs}$ which implied a pipe conductance of $0.59 \mathrm{Btu} / \mathrm{hr}-\mathrm{F}-\mathrm{ft}$ pipe.

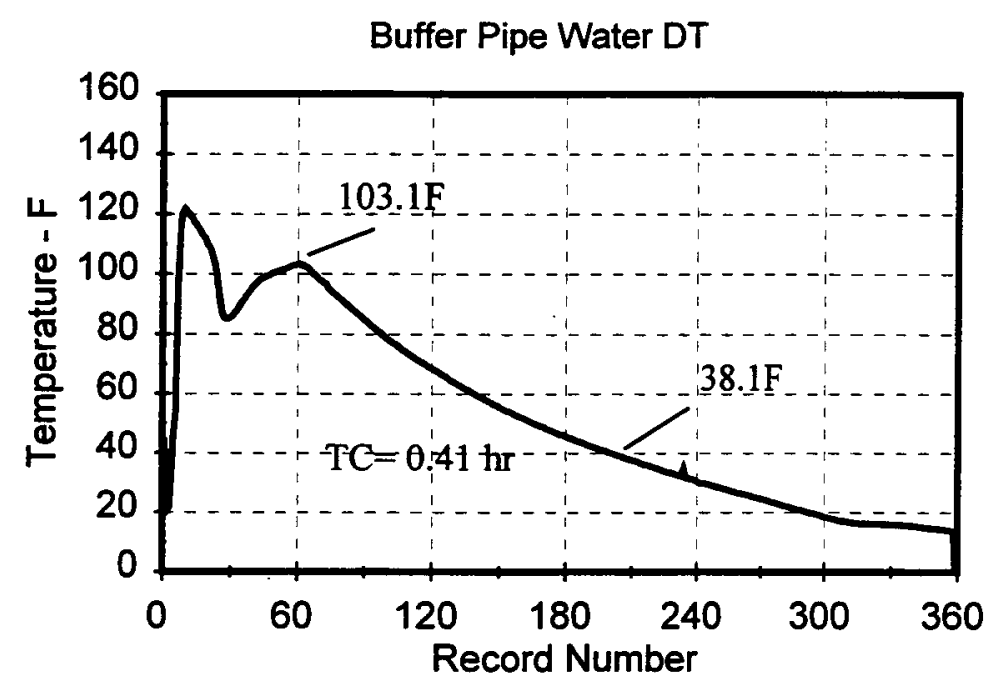

Figure 5 - Plot of buffer coil water temperature with an un-insulated coil suspended in a stirred air gap.

To confirm the bare pipe conductance for $3 / 4$-inch pipe contained in the above report a simple test ${ }^{4}$ was performed. The baseboard convectors in Zone 1 were covered to eliminate any convector induced convective air-flow over the return pipe. The return pipe water temperature in Zone 1 was examined during circulation "on" and "off" periods. Figure 6 shows the results of that tests. The measured time constant was 0.59 hrs and the calculated conductance was $0.41 \mathrm{Btu} / \mathrm{hr}-\mathrm{F}-\mathrm{ft}$ pipe. This figure almost exactly confirmed the value contained in the above report.

4 (File: tdzidecy.wb2) 


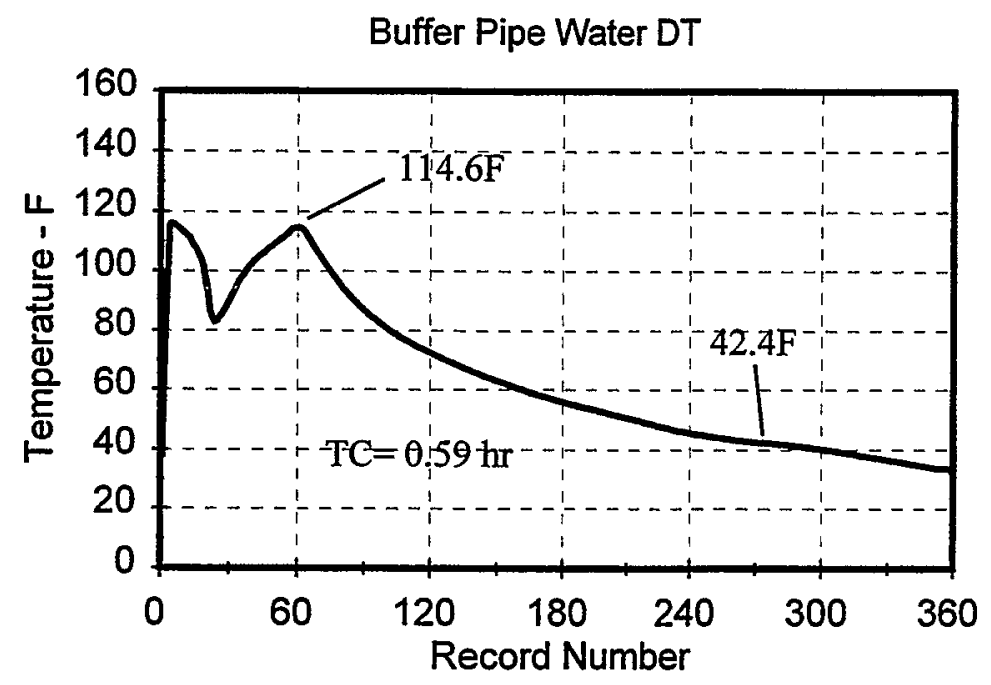

Figure 6 - Plot of the Zone 1 bare pipe water temperature in still air.

\section{Tests of the Exaggerated System}

As mentioned earlier the test results thus far have been inconclusive. In order to put the issue to rest an exaggerated system was configured as a modification of the original test system. This exaggerated system incorporated half of the distribution, namely Zone 2 and an additional buffer. The buffers each used a lightly insulated pipe coil suspended in a stirred air gap. The intent here was to examine a distribution system that minimized useful heat to the space and maximized wasted heat to the buffer zone.

The flow meter readings for the exaggerated system were redone to ensure that the new configuration was accurately measured. The timed tests during operation of the system with the boiler in the loop and bypassed showed a small difference from previous full system readings. With the boiler in the loop the readings averaged $2.94 \mathrm{gpm}$. With the boiler out of the loop the flow averaged $3.28 \mathrm{gpm}$. Assuming the $-0.08 \mathrm{gpm}$ error, measured earlier, the average flows used in this analysis are $2.86 \mathrm{gpm}$ and $3.2 \mathrm{gpm}$ respectively.

A pair of tests were performed on the exaggerated system which duplicated the operational pair of the distribution system tests conducted earlier. In this pair of tests ${ }^{5}$ the two buffer pipe coils were lightly insulated and the air gaps were stirred using small air fans. The first of this pair of tests, an un-purged test (boiler in the loop), used a circulator "on" time of 10 minutes and a circulator "off" time of 50 minutes. The second, a purged test (boiler bypassed and out of the loop), used a circulator "on" time of 20 minutes and an "off" time

5 (Files: td022399.wb2 and td022699.wb2) 
of 40 minutes. The boiler was bypassed at 10 minutes after the circulator started allowing the distribution system to purge for 10 minutes. The circulator and bypass were shut off together.

The tests of the exaggerated system seemed to prove that the benefits of purging of the distribution system were non-existent. The results are shown in Tables $4 \mathrm{a}$ and $4 \mathrm{~b}$. The average $\mathrm{DE}$ with the boiler in the loop was 0.601 while with the boiler bypassed and the system purged the resulting average DE was 0.597 .

Table 4a - Test 1 using two lightly insulated coils each in a stirred air gap (circulator -10 minutes, boiler in the loop)

\begin{tabular}{||c|c|c|c|}
\hline Cycle Num. & $\begin{array}{c}\text { Boiler Heat } \\
\text { (btu) }\end{array}$ & $\begin{array}{c}\text { Buffer Heat } \\
\text { (btu) }\end{array}$ & $\begin{array}{c}\text { Delivery } \\
\text { Effectiveness }\end{array}$ \\
\hline 2 & 7262 & 2908 & 0.6 \\
\hline 3 & 6963 & 2778 & 0.601 \\
\hline 4 & 7001 & 2781 & 0.603 \\
\hline
\end{tabular}

Table $4 \mathrm{~b}$ - Test 2 using two lightly insulated coils each in a stirred air gap (circulator - 20 minutes, bypass valve - 10 minutes, boiler out of the loop)

\begin{tabular}{|c|c|c|c|}
\hline Cycle Num. & $\begin{array}{c}\text { Boiler Heat } \\
\text { (btu) }\end{array}$ & $\begin{array}{c}\text { Buffer Heat } \\
\text { (btu) }\end{array}$ & $\begin{array}{c}\text { Delivery } \\
\text { Effectiveness }\end{array}$ \\
\hline 2 & 7162 & 2870 & 0.599 \\
\hline 3 & 6711 & 2732 & 0.593 \\
\hline 4 & 6760 & 2717 & 0.598 \\
\hline
\end{tabular}

The final two tests ${ }^{6}$ of the exaggerated system used a 5-minute and 10-minute delays respectively, from burner "off" (with circulator "on" and boiler in the loop) to distribution system purge (circulator "on" and boiler bypassed). During each delay the circulator was "off". The thought here was that delaying the onset of purging might give the hot water in the finned-tube units a chance to reject much of its heat before it was circulated around the system.

From the data reduction it became apparent that for some reason only the first cycle of the 5 minute delay was valid; the circulator was incorrectly "on" for the delay in cycles 2,3 , and 4. The data collected for the 10 minute delay was correct for all cycles. For this reason, the results of the un-purged 10 -minute on-time test (Table $5 \mathrm{a}^{7}$ ) were used as a basis of comparison for all of the purged-with-delay tests shown in Tables $5 \mathrm{~b}$ and $5 \mathrm{c}$.

6 (Files td042799.wb2 and td042899.wb2)

7 (Based on file 022399.wb2 (normal operation)) 
Table 5a - Base test using two lightly insulated coils each in a stirred air gap (circulator - 10 minutes, boiler in the loop)

\begin{tabular}{|c|c|c|c|}
\hline \hline Cycle Num. & $\begin{array}{c}\text { Boiler Heat } \\
\text { (btu) }\end{array}$ & $\begin{array}{c}\text { Buffer Heat } \\
\text { (btu) }\end{array}$ & $\begin{array}{c}\text { Delivery } \\
\text { Effectiveness }\end{array}$ \\
\hline 1 & 7161 & 3140 & 0.595 \\
\hline 2 & 7262 & 2908 & 0.6 \\
\hline 3 & 6963 & 2778 & 0.601 \\
\hline 4 & 7001 & 2781 & 0.603 \\
\hline
\end{tabular}

Table $5 b$ - Test 2 using two lightly insulated coils each in a stirred air gap (Burner and circulator "on"- 10 minutes, boiler in the loop, 5 minute delay, circulator and bypass "on"10 minutes, boiler out of the loop)

\begin{tabular}{|c|c|c|c|}
\hline Cycle Num. & $\begin{array}{c}\text { Boiler Heat } \\
\text { (btu) }\end{array}$ & $\begin{array}{c}\text { Buffer Heat } \\
\text { (btu) }\end{array}$ & $\begin{array}{c}\text { Delivery } \\
\text { Effectiveness }\end{array}$ \\
\hline 1 & 6681 & 2783 & 0.583 \\
\hline
\end{tabular}

Table 5c - Test 2 using two lightly insulated coils each in a stirred air gap (Burner and circulator "on"- 10 minutes, boiler in the loop, 10 minute delay, circulator and bypass "on"10 minutes, boiler out of the loop)

\begin{tabular}{||c|c|c|c|}
\hline \hline Cycle Num & $\begin{array}{c}\text { Boiler Heat } \\
\text { (btu) }\end{array}$ & $\begin{array}{c}\text { Buffer Heat } \\
\text { (btu) }\end{array}$ & $\begin{array}{c}\text { Delivery } \\
\text { Effectiveness }\end{array}$ \\
\hline 2 & 6761 & 2912 & 0.569 \\
\hline 3 & 6801 & 3011 & 0.557 \\
\hline 4 & 6752 & 3030 & 0.551 \\
\hline
\end{tabular}

Here the average $\mathrm{DE}$ with the boiler in the loop based in Table 5a is 0.6 . In the purged mode the system DE is 0.58 and 0.56 based on Tables $5 \mathrm{~b}$ and $5 \mathrm{c}$ respectively.

\section{Summary}

In the first and second tests, where a system purge of 5 and 10 minutes after burner "off" was applied, the (DE) gain through purging was essentially zero. In the next series of tests, using a "buffer" which was more highly conductive, a system purge of 10 minutes after burner "off" resulted in a slight degradation of the DE.

A series of tests were performed in an attempt to identify any benefits of purging. These tests used an exaggerated distribution system consisting of half the original heat-transfer units and double the "buffer" size. The first group of these tests allowed the distribution system to purge for 10 minutes after the burner "off". Again the results showed no net gain in $\mathrm{DE}$ for the purging strategy. 
Two final tests were conducted with the thought that stagnating the flow and delaying the onset of purging might give the hot water in the distribution system a chance to reject some its heat to the conditioned space before it was circulated around the system. The tests used 5-minute and 10-minute delays from burner "off" (with circulator "on" and boiler in the loop) to distribution system purge (circulator "on" and boiler bypassed). During each delay the circulator was "off". The results from these tests each showed a small degradation in $\mathrm{DE}$ for the purge mode of operation.

\section{Conclusions}

The findings of the experiment show that any benefit in $\mathrm{DE}$ to be gained by applying a purging strategy to the distribution system alone is insignificant and may be detrimental.

The way a "buffer" is configured for a test, such as the one in this report, will have an effect on the conductance of the "buffer" piping being simulated. In addition, this method simulation can have some effect on the distribution system $\mathrm{DE}$ that is being tested.

Direct immersion of lightly insulated pipe in cube ice seems to result in a "buffer" pipe conductance which is too low. This same lightly insulated pipe suspended in an air gap which cooled by cube ice, such as used in this experiment, will yield a pipe conductance close to what can be expected for bare pipe in still air or about $0.4 \mathrm{Btu} / \mathrm{hr}-\mathrm{F}$-ft pipe. On the other hand, bare pipe in a similar air gap will have a conductance which is too high.

The results of these tests show that an increase of the distribution system heat loss to the "buffer" can result in an overall degradation of the DE. In one test an increase of the simulated pipe conductance resulted in a slight degradation of the DE amounting to about 1 percent. In the last tests, using an exaggerated system, the degradation was more pronounced ranging from about 3 to 7 percent.

\section{References}

[1] American Society of Heating, Refrigerating, and Air Conditioning Engineers (ASHRAE) 1999. Standards Project Committee 152P draft standard (unpublished). 1791 Tullie Circle N.E., Atlanta, GA 30329-2305

[2] Andrews, J. W., Design Predictions and Diagnostic Test Methods for Hydronic Heating Systems in ASHRAE Standard 152P, BNL Informal Report 63200 